\title{
TEKNIK SCROLL UNTUK PEMBUATAN PRODUK INTERIOR
}

\author{
Andono \\ Aruman *) \\ ABSTRACT
}

In the world of crafts, especially wood craft, some techniques have been known to create a work of art such as carving, lathing, scrolling, etc. Scroll technique is the work of wood craft production using scrolling tools such as scrollsaw, which is a saw with small ribbon powered by electricity. The tool has the specifications of cutting perpendicular, oblique, straight, and curved positions. This device is usually used as a tool to make holes in the process of wood carving (krawangan), or to cut the carving edge. In addition, scroll saw is usually used to make puzzle (education props / toys), and letters.

With its specifications, scrollsaw can be explored further by making it as a major tool in the manufacture of wood craft art, such as interior elements. Our preliminary research proved that the tool can be used as the main tool for the manufacture of wood craftsmanship products (decorative masks) that is unique and distinctive. So in this study we try scroll technique for the manufacture of some products for interior elements, such as mirrors, wall clocks, table / wall lamps, and the flowerpots. The manufacturing process consists of some stages such as explorating, designing, embodying, and evaluating. By exploring the scroll technique, planks of wood that are cut will produce a curved piece and form a small square field. If the blades are arranged with the arrangement that is designed with a particular composition, they will bear a certain distinctive and unique motive form in their field surface. The product of the interior elements will have distinctiveness, uniqueness, and attractiveness of their own.

Scroll technique can be developed for the manufacture of art craft products because the scrollsaw is easy enough to use. Therefore, this scroll technique can be used as a new job opportunity for people who want to be engaged in it to reduce the number of unemployed people. Being creative with the scroll technique can be engaged professionally or just as a hobby for works of art.

Keywords: scroll techniques, craft product, interior elements

\section{ABSTRAK}

Dalam dunia seni kriya, khususnya kriya kayu, dikenal beberapa teknik untuk mewujudkan sebuah karya seni seperti teknik ukir, teknik bubut, teknik skrol (scroll), dsb. Teknik scroll adalah teknik produksi karya kriya kayu dengan menggunakan alat gergaji skrol (scrollsaw), yaitu alat gergaji berpita kecil yang digerakkan dengan tenaga listrik. Alat tersebut

\footnotetext{
* Andono (and_and ono@yahoo.co.id), Aruman (aruman_ssn@yahoo.com) Staf Pengajar Program Studi Kriya Seni, Jurusan Kriya, Fakultas Seni Rupa, Institut Seni Indonesia Yogyakarta
} 
memiliki Spesifikasi: memotong tegak lurus, memotong miring, memotong lurus, dan lengkung. Dengan spesifikasi yang dimiliki, scrollsaw dapat dieksplorasi lebih jauh lagi dengan menjadikannya sebagai alat utama dalam pembuatan produk/karya seni kriya kayu, seperti elemen interior. Penelitian pendahuluan yang pernah kami dilakukan membuktikan bahwa alat tersebut dapat dipakai sebagai alat utama untuk pembuatan produk seni kriya kayu (topeng hias) yang unik dan khas. Maka dalam penelitian ini teknik scroll akan dicoba untuk pembuatan beberapa produk untuk elemen interior, seperti kaca rias, jam dinding, lampu meja/dinding, dan tempat pot bunga. Adapun proses pembuatannya melalui tahapan-tahapan seperti eksplorasi, perancangan, perwujudan, dan evaluasi. Dengan mengeksplorasi teknik scroll, bilah-bilah kayu yang dipotong akan menghasilkan potongan melengkung dan membentuk bidang-bidang kotak kecil. Apabila bilah-bilah tersebut disusun dengan susunan yang didesain dengan komposisi tertentu akan melahirkan bentuk motif tertentu yang khas dan unik pada permukaan bidangnya. Produk elemen interior yang dihasilkan akan memiliki kekhasan, keunikan, dan kemenarikan tersendiri.

Teknik scroll dapat dikembangkan untuk pembuatan produk-produk seni kriya, karena alat scrollsaw cukup mudah untuk dioperasionalkan. Oleh karena itu teknik scroll ini dapat dijadikan sebagai peluang pekerjaan baru bagi masyarakat yang mau menekuninya, sehingga dapat mengurangi jumlah pengangguran. Berkreasi dengan teknik scroll tersebut dapat ditekuni secara professional maupun sekedar sebagai hoby berkarya seni.

Kata kunci: teknik scoll, produk seni kriya, elemen interior.

\section{PENDAHULUAN}

Teknik scroll merupakan salah satu teknik produksi karya kriya kayu yang menggunakan alat gergaji skrol (scrollsaw), yaitu alat gergaji berpita kecil yang digerakkan dengan tenaga listrik. Alat tersebut memiliki fungsi yang spesifik dalam memotong kayu dengan posisi tegak lurus, memotong miring, memotong lurus, dan memotong lengkung. Alat ini biasa digunakan sebagai alat bantu untuk membuat lubang dalam proses mengukir kayu bentuk krawangan (ukir tembus), atau untuk memotong bagian pinggir ukiran. Selain itu, alat scrollsaw juga dipakai untuk membuat alat mainan edukasi berupa puzzle dan letter (Gambar 1 dan 2).

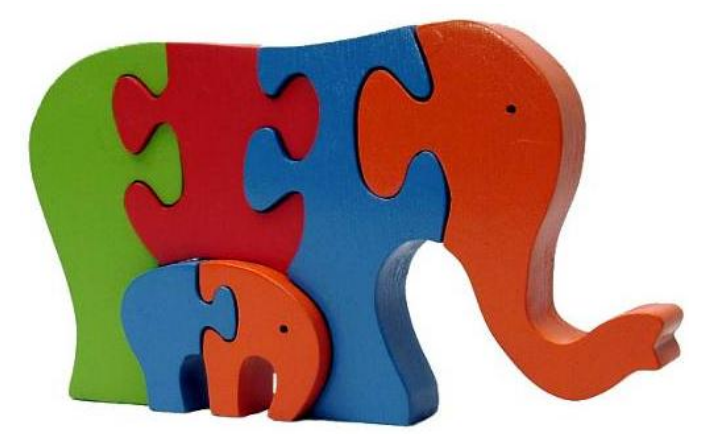

Gambar 1. Jigsaw Puzzle - Elephant with 1 Child Size: $6 \times 2 \times 10 \mathrm{~cm}$ (Foto: koleksi Mandiri Craft, 2012) 


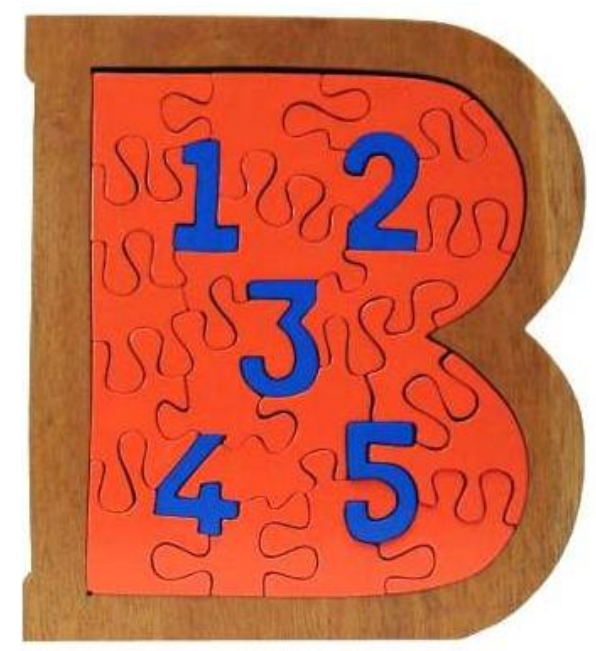

Gambar 2. Jigsaw Puzzle - Alphabet B

Size: $2 \times 13 \times 17 \mathrm{~cm}$

(Foto: koleksi Mandiri Craft, 2012)

Memanfaatkan teknik scroll dalam menciptakan produk-produk kriya guna keperluan elemen interior berbahan kayu telah banyak dilakukan, karena teknik ini memiliki banyak keunggulan dan kemudahan. Beberapa keunggulan tersebut antara lain: (1) Dapat membentuk lubang dengan akurasi cukup detail berdasarkan garis gambar yang telah ditentukan ukurannya, contoh dapat dilihat pada gambar Miniatur The Ferris Wheel (gambar 1); (2) Pada saat pembentukan dengan teknik scroll dapat muncul menjadi dua wujud, yakni bentuk positif dan negatif, bentuk timbul dan bentuk lubang (3) Dapat membentuk bidang yang sama lebih dari satu dalam sekali proses dengan cara ditumpuk.

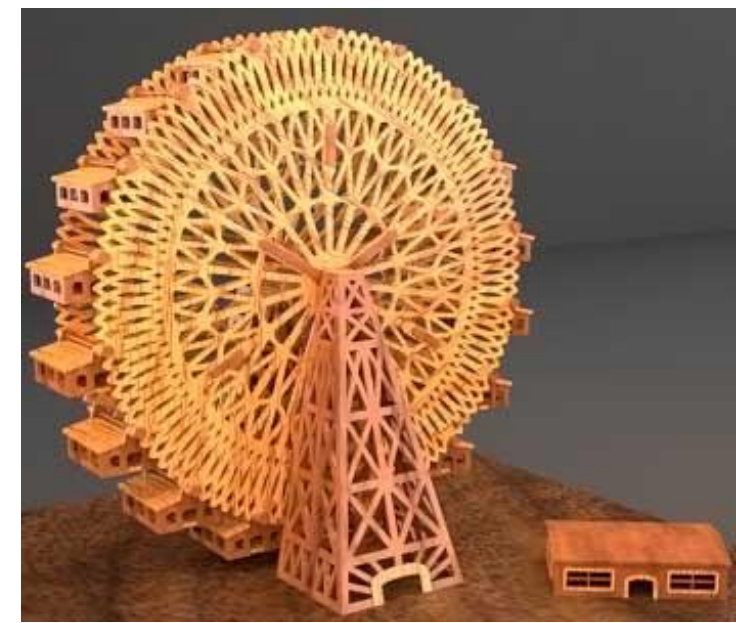

Gambar 4. Miniatur The Ferris Wheel

(Sumber: www.finescrollsaw.com)

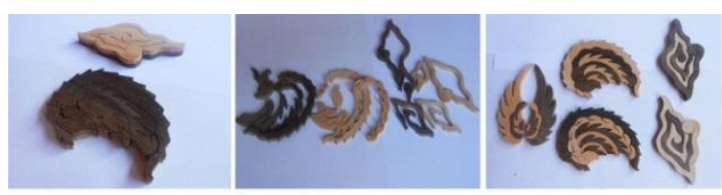

Gambar 5. perhiasan anting kayu jati dan sonokeling menggunakan teknik scroll positif negatif

(Foto: Aruman, 2012)

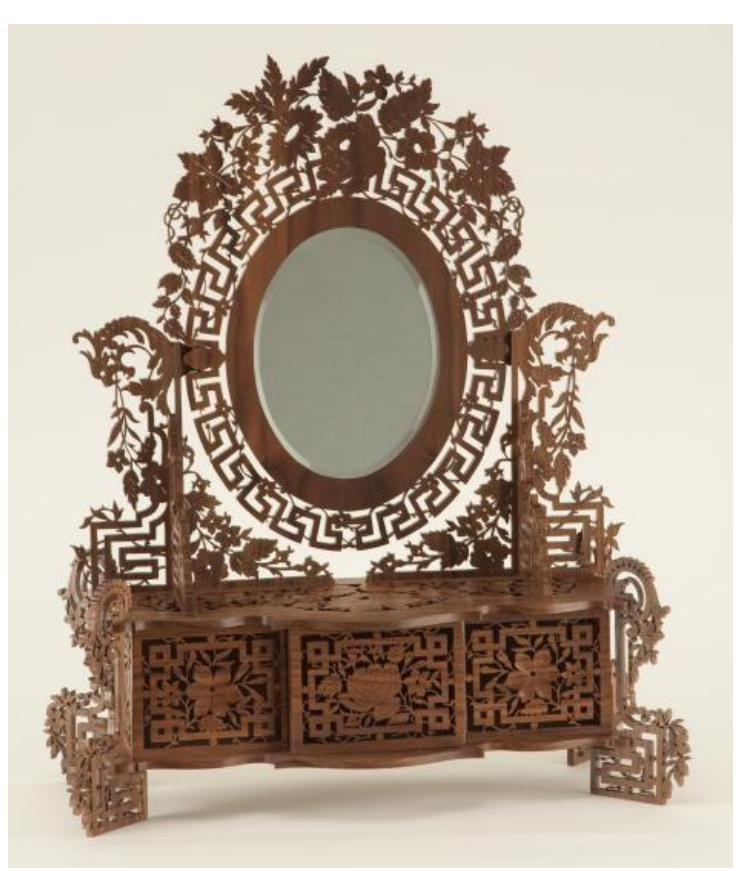

Gambar 6. french mirror karya Doris Gibson

(Sumber: http://pinterest.com/)

Berdasarkan keunggulan dan kemudahan dalam pemakaiannya, teknik 
scroll dapat lebih diberdayakan atau ditingkatkan penerapannya dalam penciptaan karya seni kriya yang kreatif dan inovatif. Teknik scroll memiliki spesifikasi kerja memotong secara tegak lurus maupun miring, baik bentuk lurus maupun lengkung. Lengkungan yang berukuran kecil sekalipun, yang sulit dikerjakan dengan gergaji lain, dapat dikerjakan dengan teknik scroll. Dengan teknik tersebut proses pengerjaan dapat dilakukan dengan lebih cepat karena digerakkan oleh dinamo elektrikal, sehingga produktivitas karya yang dihasilkan lebih banyak dibandingkan dengan teknik scroll manual. Selain itu kualitas bentuk maupun potongan yang dihasilkan lebih rapi dan presisi sesuai dengan pola.

Pada penulisan artikel ini, penulis mencoba memfokuskan pembahasan pada proses prenciptaan karya kriya kayu dengan teknik scroll sebagai bahasan utamanya. Dalam sub bab pembahasan akan diulas mengenai dasar pembuatan desain (eksplorasi bentuk) karya yang dibuat agar ada kesesuaian dengan spesifikasi alat, cara kerja alat, capaian bentuk yang dapat dipotong, karakter hasil potongan, dan jenis kayu yang digunakan. Artikel yang diadaptasi dari hasil penelitian penciptaan ini juga akan menyajikan karya hasil eksperimen berupa kap lampu, pigura kaca cermin, jam dinding, dan tempat pot bunga.

\section{METODE}

\section{Metode Eksplorasi}

Metode ini dilakukan untuk mendapatkan masukan tentang hal-hal yang berkaitan dengan bidang garap, bertujuan untuk memperoleh pengetahuan dan informasi tentang hal-hal yang berkaitan dengan sumber ide penciptaan dan proses perwujudan yang dilakukan, antara lain: 1) Eksplorasi alat dilakukan untuk mendapatkan informasi dan pengamatan secara mendalam terhadap alat, meliputi spesifikasi bentuk, ukuran, cara kerja, hasil kerja, 2) Eksplorasi bentuk karya untuk pengembangan imajinasi bentuk karya yang sesuai dengan spesifikasi alat, untuk menemukan bentuk karya yang terbaik dapat dicapai melalui pembuatan beberapa sketsa alternatifnya, kemudian diseleksi sketsa terbaik untuk dikembangkan dalam designing.

\section{Metode Eksperimen}

Eksperimen bahan dilakukan untuk mengenal karakter bahan yang digunakan, seperti bahan papan kayu buatan (multipleks) dan kayu alam. Selain eksperimen bahan, juga dilakukan Eksperimen disain, yaitu membuat model beberapa desain yang telah dibuat dengan bahan gabus sintetis (styrofoam).

\section{Metode Pembentukan}

a. Designing: membuat sketsa alternatif, memilih sketsa terbaik, membuat gambar kerja dari sketsa terpilih yang memung-kinkan untuk diwujudkan.

b. Persiapan bahan baku: menyediakan kayu yang dipilih.

c. Persiapan bahan bantu: gabus sintetis (styrofoam).

d. Persiapan alat utama: gergaji bobok.

e. Persiapan alat bantu dan finishing: pahat kayu, palu, paku, lem, ampelas, kuas, pisau cutter. 
f. Pembuatan model: berdasarkan desain yang telah dibuat dicoba diwujudkan dengan bahan gabus sintetis (styrofoam).

g. Pembuatan karya jadi: meliputi kerja pengemalan, pemotongan, pengampelasan, perangkaian, penyempurnaan ben-tuk, dan finishing.

\section{PEMBAHASAN}

\section{Proses Kreatif}

Penelitian/perancangan karya seni ini menggunakan teori proses penciptaan yang dikemukakan oleh Gustami SP. (Gustami SP, 2004:29-32) bahwa terdapat tiga tahap dan enam langkah dalam proses penciptaan karya seni kriya, yaitu:

1. Eksplorasi, meliputi (a) Pengembaraan jiwa, pengamatan lapangan, dan penggalian sumber informasi meliputi kegiatan penggalian ide-ide melalui abstraksi kejiwaan yang berkaitan dengan topik penelitian/perancangan. Tahapan ini menghasilkan apa yang melatar belakangi dilakukannya penelitian/perancangan;

Pengamatan lapangan dilakukan setelah ditemukan topic penelitian/perancangan, yang dalam hal ini dilakukan pengamatan terhadap alat gergaji skrol/scrollsaw sebagai alat yang digunakan dalam teknik scroll; (c) Langkah penggalian landasan teori di antaranya menghasilkan teori proses penciptaan karya seni kriya sebagaimana telah disampaikan di atas. Selain itu diperoleh pula deskripsi yang berkaitan dengan mesin skrol. Penggalian acuan visual diperoleh gambar beberapa elemen interior seperti jam dinding, kap lampu, dan tempat pot bunga.

2. Perancangan, untuk merancang yang tepat dan efektif seorang perancang harus mempunyai cara terbaik agar rancangan dapat dibentuk, dibuat, digunakan dan dikaitkan dengan lingkungan (Wucius Wong, 1986: 1). Adapun tahap perancangannya adalah: (a) Penuangan ide ke dalam sketsa; (b) Penuangan sketsa ke dalam gambar teknik dilakukan dengan computer (gambar 1.) dan pembuatan model dari styrofoam (gambar 3) yang dibentuk dengan menggunakan pemotong styrofoam bertenaga listrik (gambar 2).

3. Perwujudan, (a) Mewujudkan karya berdasarkan gambar (dilakukan dengan teknik scroll); (b). Evaluasi tentang kesesuaian ide dan wujud karya seni, dan juga ketepatan fungsi.
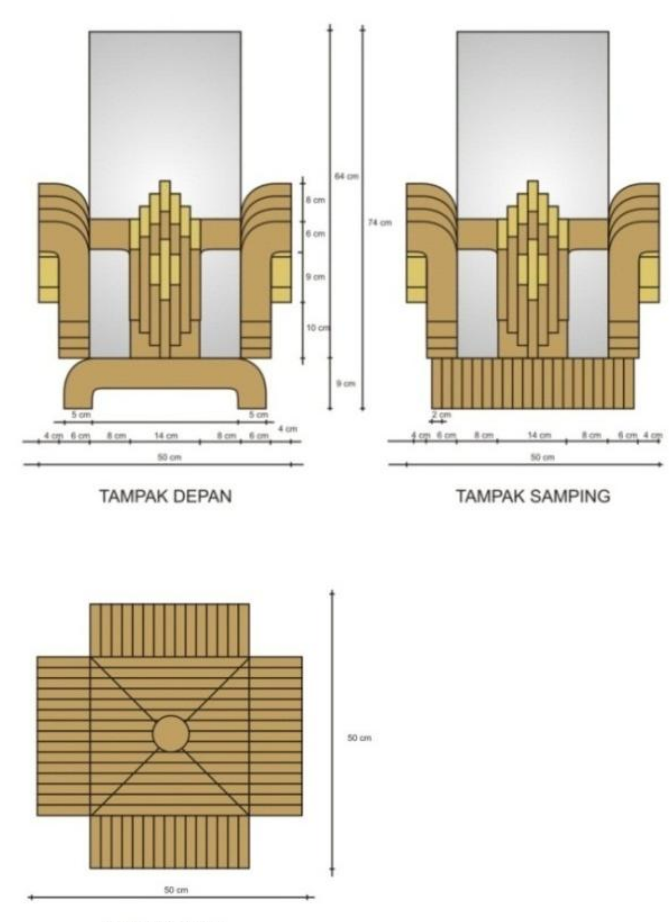

TAMPAK ATAS

Gambar 7. Desain kap lampu duduk 


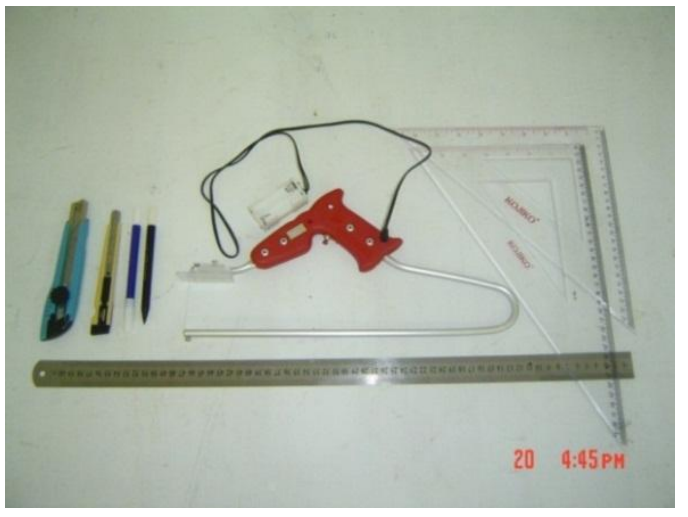

Gambar 8. Peralatan untuk pembuatan model Pisau Cutter, spidol kecil, pemotong gabus elektrik, penggaris segi tiga, dan penggaris logam.

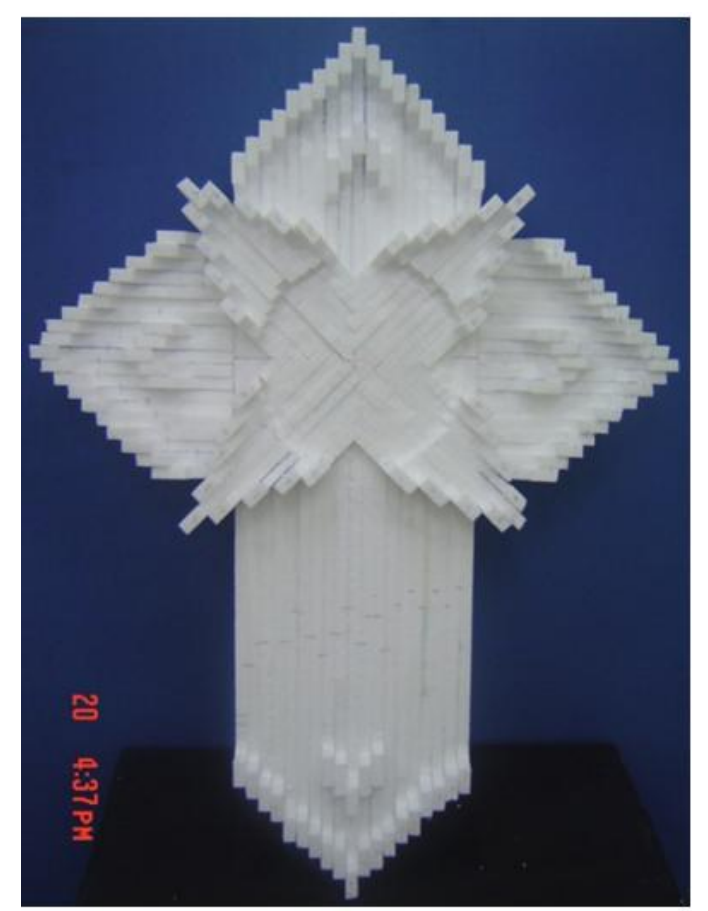

Gambar 9. Model Jam Dinding dari Styrofoam

\section{Teknik Scroll}

Teknik scroll adalah teknik produksi karya kriya kayu dengan menggunakan alat gergaji skrol (scrollsaw), yaitu alat gergaji berpita kecil yang digerakkan dengan tenaga listrik. Alat tersebut memiliki Spesifikasi: memotong tegak lurus, memotong miring, memotong lurus, dan lengkung.
Terdapat dua jenis gergaji skrol, yaitu gergaji skrol masinal dan gergaji skrol manual. Gergaji skrol masinal adalah gergaji berpita kecil yang digerakkan oleh tenaga mesin/elektrik yang dilengkapi dengan komponen-komponen lain sehingga dapat bergerak secara stabil. Gergaji skrol manual adalah gergaji berpita kecil yang dijepit atau dikencangkan pada sengkang besi berbentuk huruf $U$, bertangkai sebagai pegangan dan digerakkan dengan tangan. Alat ini biasanya disebut dengan copingsaw.

Teknik skrol biasanya digunakan dalam pembuatan produk kerajinan, seperti pembuatan puzzle, leter huruf dari kayu (lettering), membuat hiasan/ornamen yang akan diterapkan/ditempelkan pada mebel. Dengan teknik skrol dapat menghasilkan ornamen yang berpermukaan positif (timbul) dan negatif (cekung/tembus) (Moh Fathurrahman, 2006: 365).

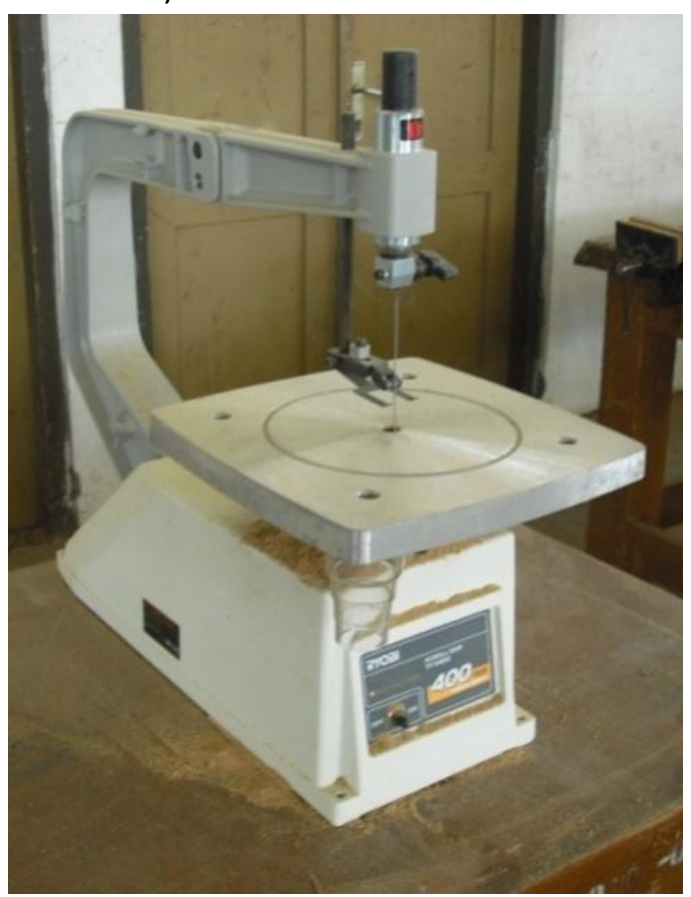

Gambar 10. Scrollsaw 


\section{Perwujudan Karya dengan Teknik Scroll}

Setelah model selesai dibuat, langkah berikutnya adalah mewujudkannya ke dalam bentuk karya/produk prototip. Adapun langkah-langkah pembuatannya adalah sebagai berikut.

1. Pembuatan bilah.

Lembaran multipleks yang memiliki ukuran besar harus dipotong potong terlebih dahulu sesuai ukuran yang diinginkan.

2. Pemolaan.

Bentuk model yang sudah dibongkar, masing-masing bilahnya dipolakan (gambar dipindahkan) pada permukaan bilah multipleks yang sudah dipotong.

3. Pemotongan/pembentukan.

Bilah-bilah yang sudah diberi gambar, selanjutnya dipotong dengan alat gergaji scroll sesuai bentuk/garis gambarnya.

4. Penyempurnaan bentuk.

Ada kemungkinan bentuk yang dihasilkan dari proses pemotongan kurang sesuai dengan bentuk yang diharapkan, maka bentuk-bentuk tersebut perlu disempurnakan agar tepat seperti bentuk modelnya.

5. Pengampelasan.

Agar permukaan bilah yang telah dibentuk dengan teknik scroll halus, maka perlu digosok dengan ampelas no. 240 dan diulang lagi dengan ampelas no. 400.

6. Merangkai bilah.

Bilah-bilah yang bentuknya sudah disempurnakan dan halus, selanjutnya dirangkai sesuai dengan bentuk model yang dibuat. Untuk merekatkannya dipakai lem kayu dan agar dapat merekat kuat dan posisinya tidah berubah/bergeser perlu dijepit dengan alat klem F.

7. Finishing.

Proses terakhir pembuatan produk prototip adalah memberi lapisan bahan finishing seperti pewarna maupun lapisan akhir/top coat. Untuk pewarnaan dapat digunakan bahan pewarna sandy dengan cara dikuaskan atau disemprotkan dengan spray gun, baru kemudian diberi lapisan aqua lacquer.

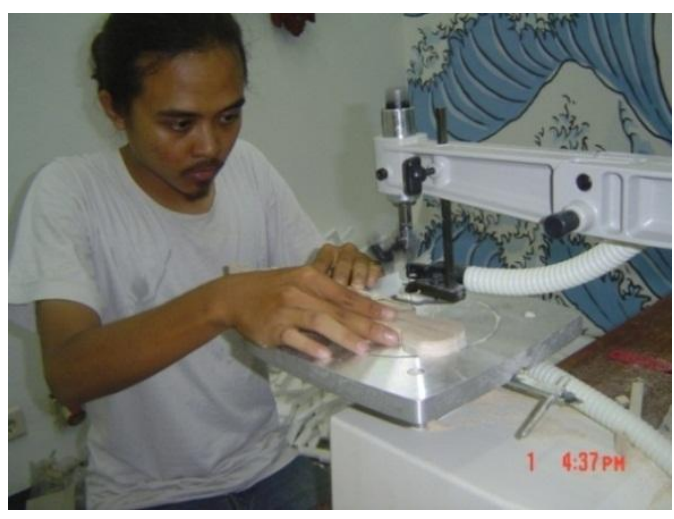

Gambar 11. Pemotongan dengan scrollsaw

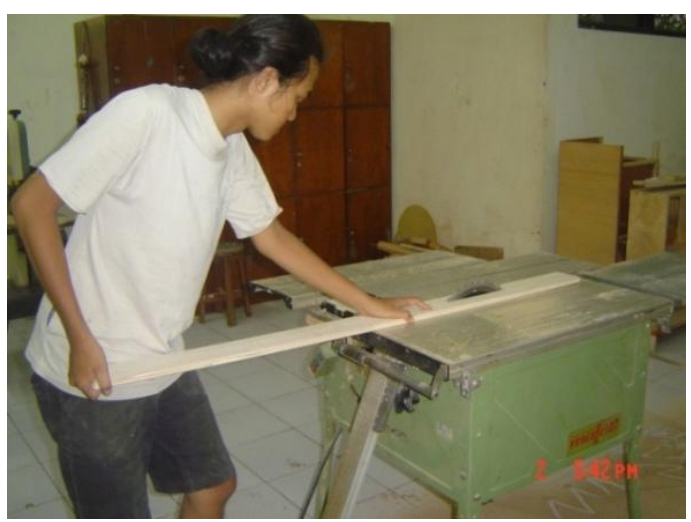

Gambar 12. Pemotongan dengan sirclesaw (pembuatan bilah) 


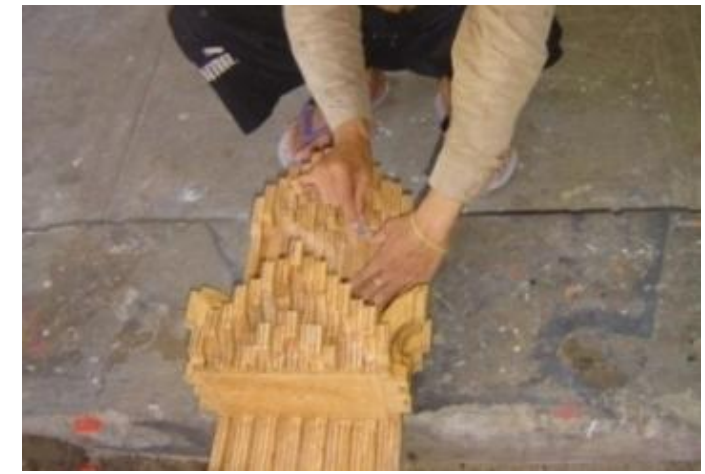

Gambar 13. Pengampelasan

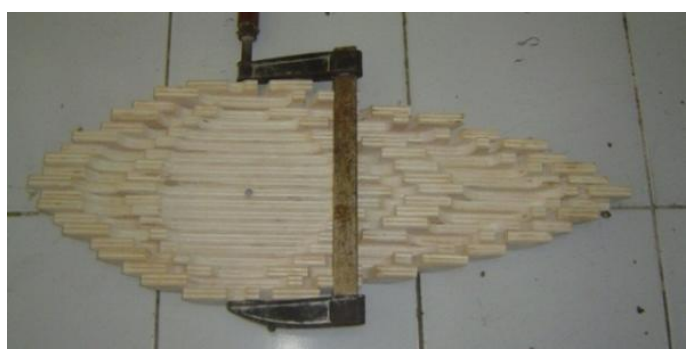

Gambar 14. Perangkaian/perekatan (pengepresan dengan klem F)

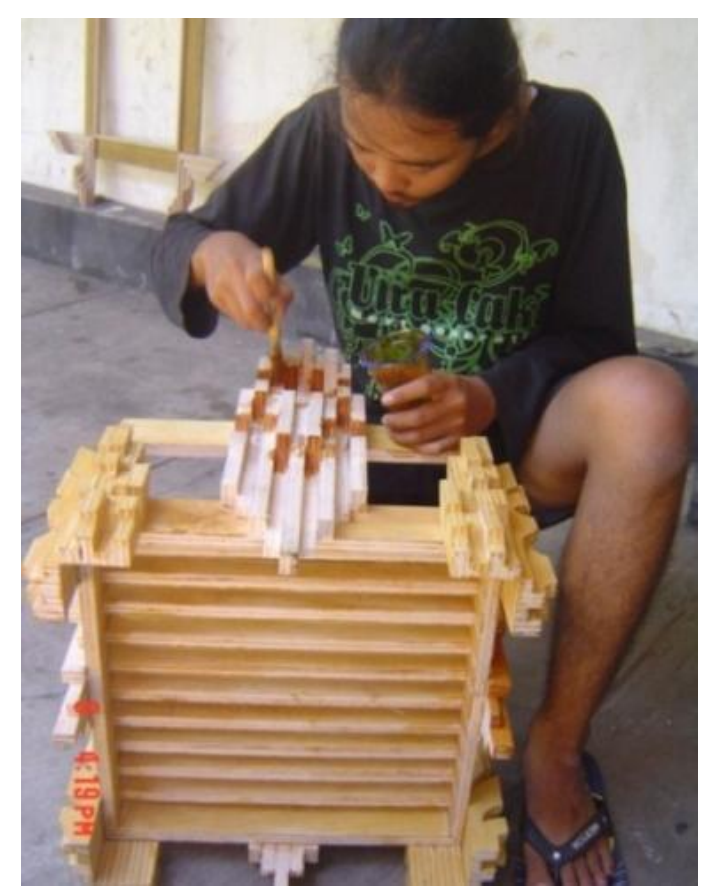

Gambar 15. Finishing/pewarnaan

\section{Produk Prototip}

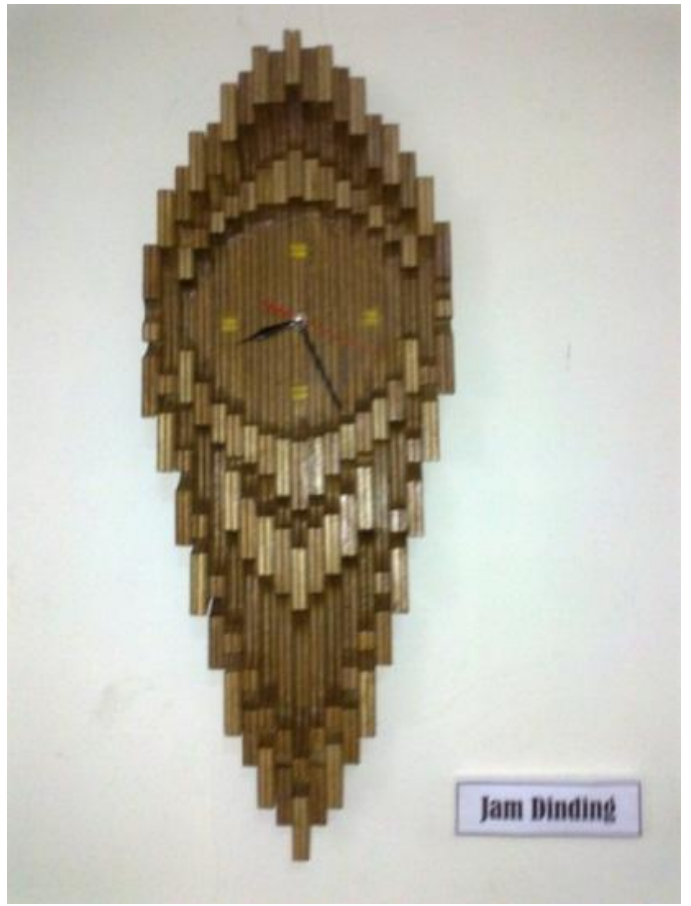

Gambar 16. Jam dinding 1

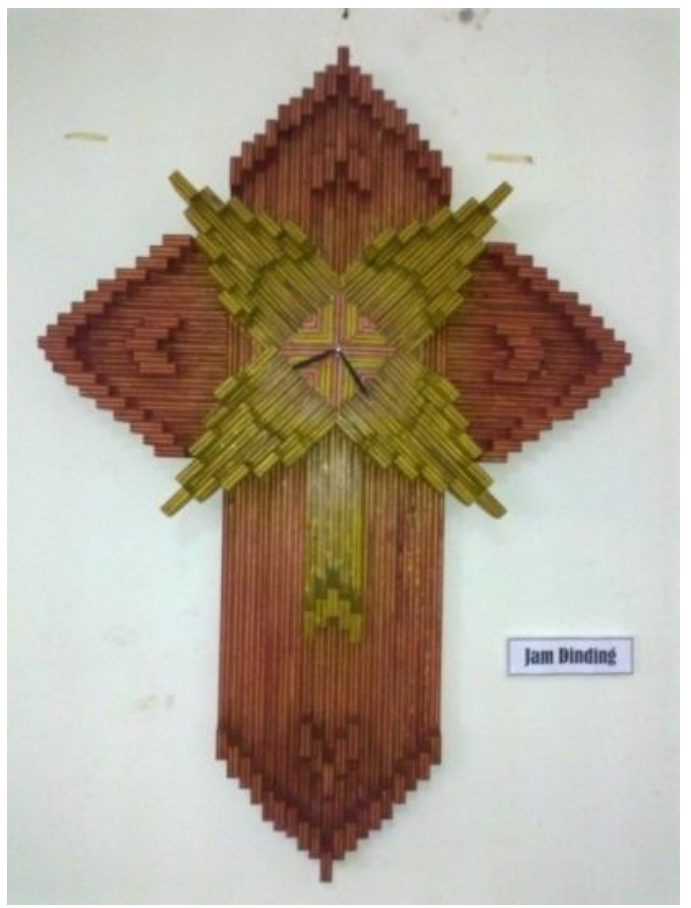

Gambar 17. Jam dinding 2 


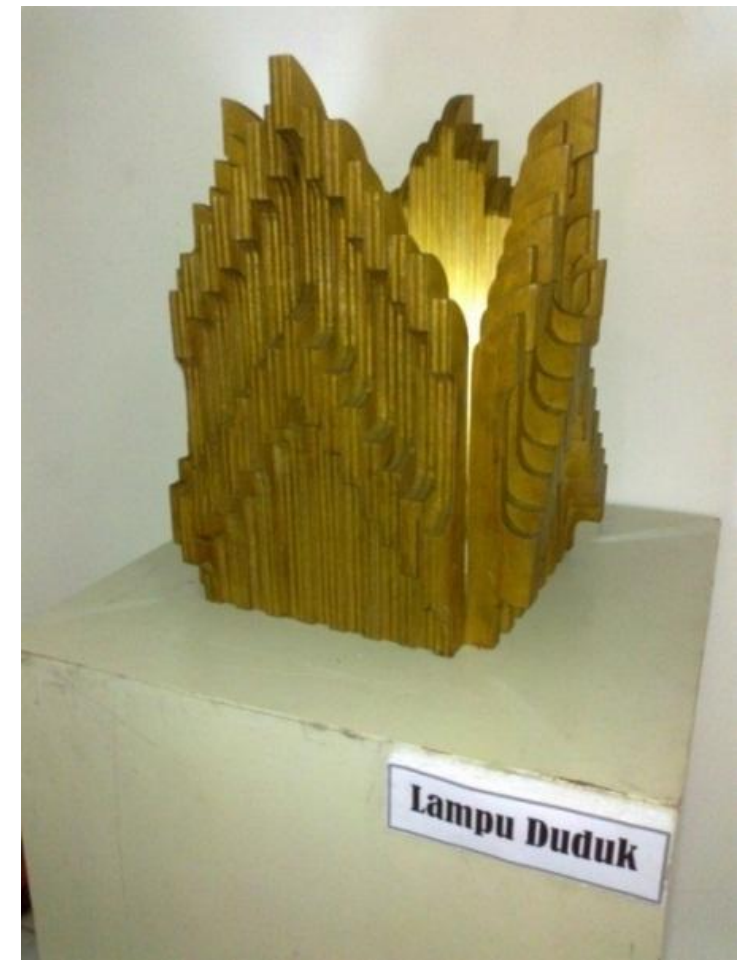

Gambar 18. Lampu duduk

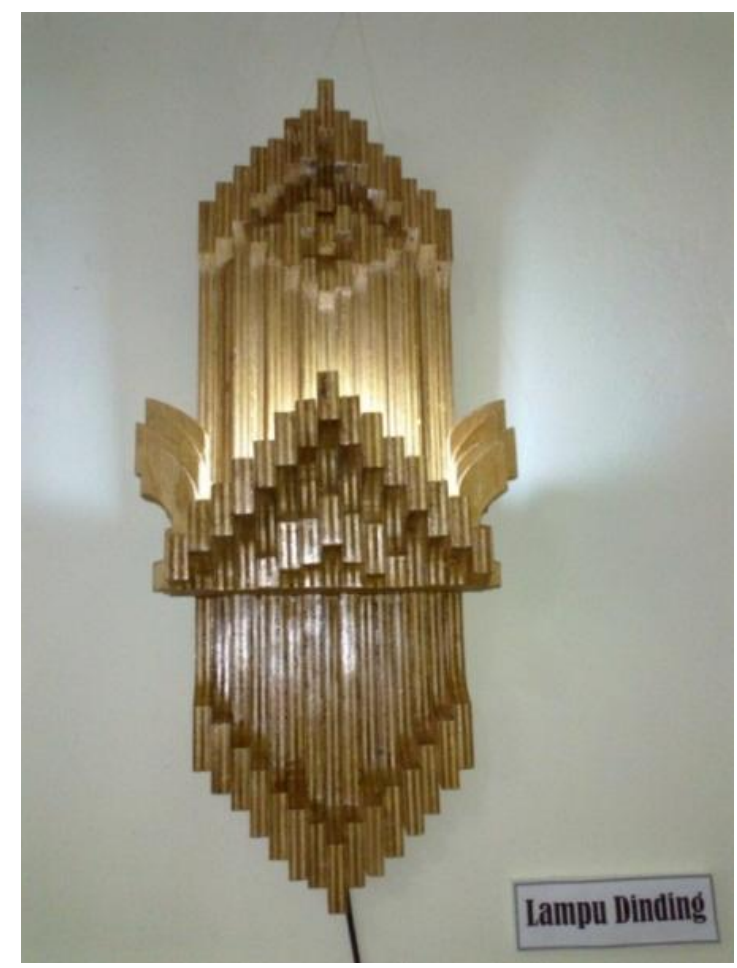

Gambar 19. Lampu dinding

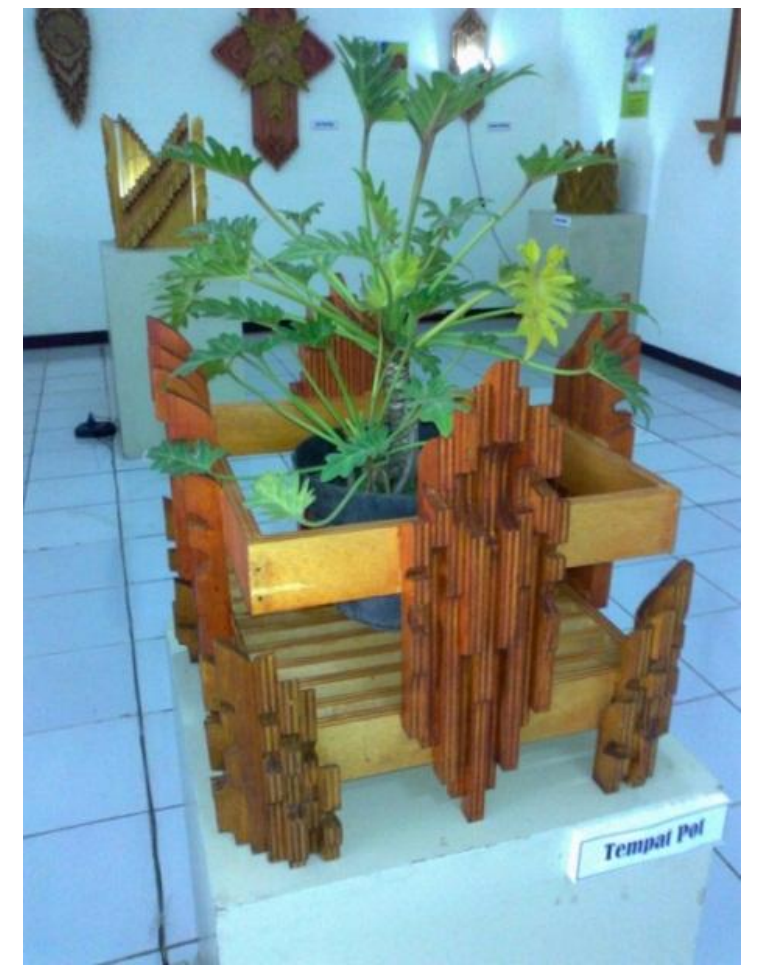

Gambar 20. Tempat pot bunga

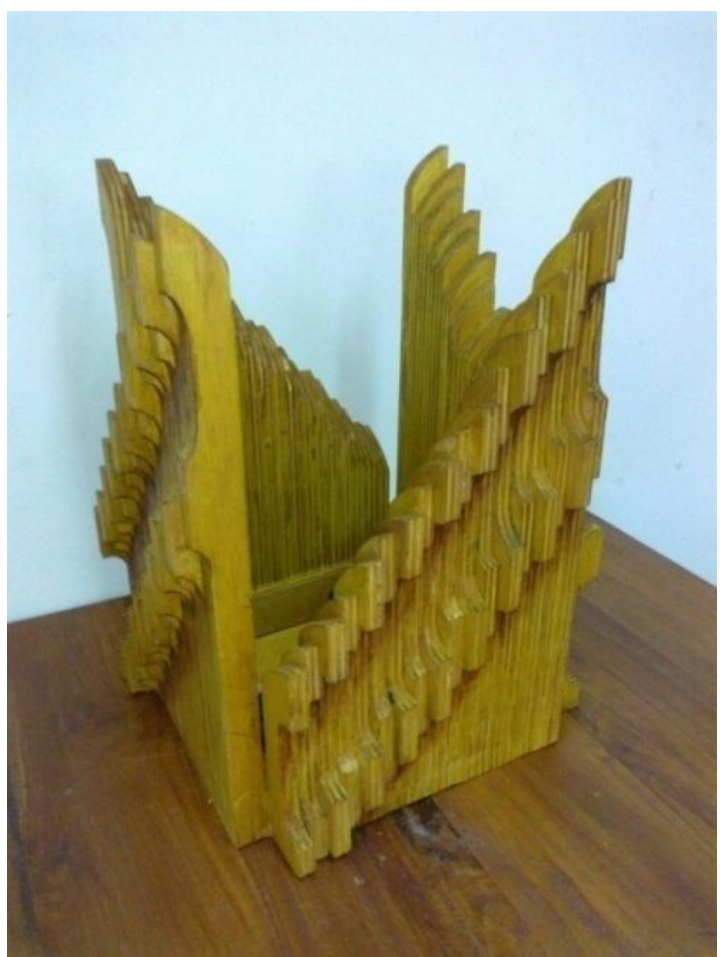

Gambar 21. Lampu duduk 


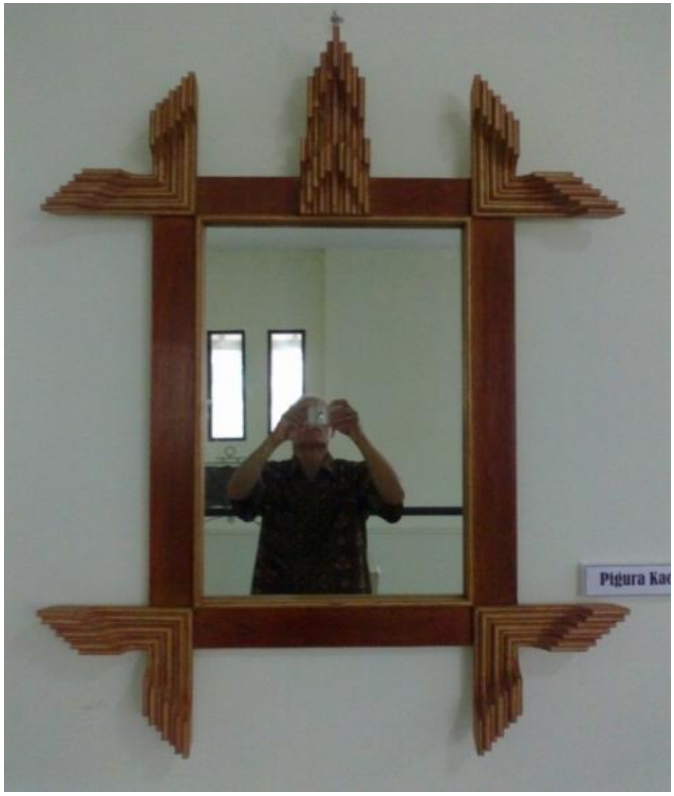

Gambar 22. Pigura / kaca cermin

\section{KESIMPULAN}

Setelah dilakukan eksperimen atas teknik scroll untuk pembuatan elemen interior menunjukkan bahwa dengan teknik scroll dapat digunakan untuk pembuatan produk berupa elemen interior yang dapat menghasilkan produk yang memiliki kekhasan dan keunikan tersendiri. Bentuk-bentuk produk yang dirancang/didesain dibuat dengan mempertimbangkan spesifikasi yang dimiliki oleh scrollsaw, sehingga semuanya memungkinkan dapat dikerjakan dengan teknik scroll tanpa kesulitan berarti. Dengan demikian hasil penelitian ini dapat disosialisasikan kepada masyarakat agar dapat dijadikan sebagai teknik tersendiri untuk membuat produk yang khas dan unik.

\section{DAFTAR PUSTAKA}

Andono, 2007. Penciptaan Topeng Hias Dengan Alat Jigsaw, Laporan
Penelitian/Perancangan, Lembaga Penelitian ISI Yogyakarta.

Budianto, A. Dodong, 1988. Mesin Tangan Industri Kayu, PIKA Semarang, Kanisius Yogyakarta.

Damanauw J.F, 2000. Mengenal Kayu, cetakan ke 11, SMTIK - PIKA Semarang, Kanisius Yogyakarta.

Faturrahman, Moh, 2006. Pengetahuan Bahan dan Alat (PBA), Politeknik Seni Yogyakarta.

Gustami SP, 2004. Proses Penciptaan Seni Kriya, Program Penciptaan Seni, Pasca Sarjana Institut Seni Indonesia Yogyakarta.

Kartapradja, Setijati, 1980. Jenis-Jenis Kayu di Indonesia, Lembaga Biologi Nasional-LIPI Bogor, PN Balai Pustaka, Jakarta.

Koch, Robert, 1997. Pedoman Gambar Kerja, Kanisius bekerja sama dengan PIKA Semarang, Yogyakarta.

Lerch, Ernst, 1987. Pengerjaan Kayu Secara Masinal, Kanisius bekerja sama dengan PIKA Semarang, Yogyakarta.

Sunaryo, Agus, 1997. Reka Oles Mebel Kayu, Kanisius bekerja sama dengan PIKA Semarang, Yogyakarta.

Tim penyusun,1986. Mengenal Sifat-Sifat Kayu Indonesia dan Penggunaannya, PIKA Semarang, Kanisius Yogyakarta. 